\title{
Health Promoting Behaviors and Risk of Cardiovascular Events among Patients with Cardiovascular Diseases
}

\author{
Anggi Lukman Wicaksana ${ }^{1,2 *} \mathbb{D}$, Erika Maharani ${ }^{3}$, Hsing-Mei Chen $^{4}$ \\ ${ }^{1}$ Department of Medical Surgical Nursing, Universitas Gadjah Mada, Yogyakarta, Indonesia; ${ }^{2}$ The Sleman Health and \\ Demographic Surveillance System, Universitas Gadjah Mada, Indonesia; ${ }^{3}$ Department of Cardiology and Vascular, Universitas \\ Gadjah Mada/Dr. Sardjito General Hospital, Yogyakarta, Indonesia; ${ }^{4}$ Department of Nursing, National Cheng Kung University, \\ Tainan, Taiwan, ROC.
}

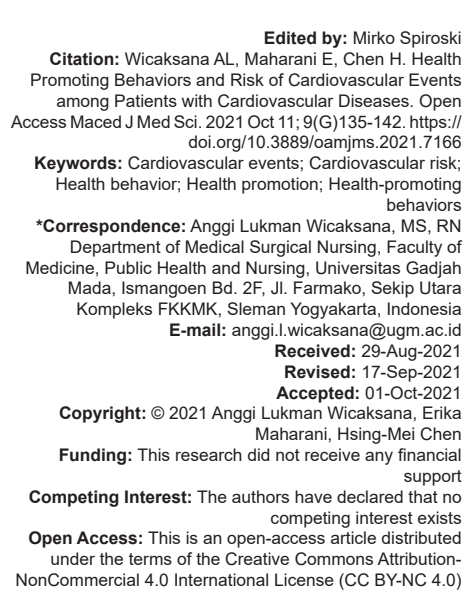

Introduction

Cardiovascular diseases (CVD) are a group of important public health concerns and a significant cause of death around the world. CVD contributes to 17.5 million global deaths or $31 \%$ of the overall causes of death worldwide. Approximately, $82 \%$ of deaths due to non-communicable diseases occur in low-and middleincome countries where CVD accounts for $37 \%$ [1]. In Indonesia, one of the low-and middle-income countries, CVD accounts for $37 \%$ of total deaths with smoking and hypertension as the major risk factors [2].

Patients with CVD are known to have the risk of cardiovascular events, in which stroke and heart attack are common forms, based on their present health status and behaviors. People with risk factors, for instance, presence of diabetes, hyperlipidemia, elderly, and smoker also have increased chances to develop cardiovascular events although they have not been diagnosed with CVD yet [3], [4], [5]. The common risk of CVD is for fatal events such as heart attack and stroke [6]. There are four levels of risk of cardiovascular events among CVD patients; low, moderate, high, and very high-risk regarding fatal or non-fatal events [3], [5], [6], [7]. Having a low risk of cardiovascular event does not mean that someone does not have any risk at all. As a consequence, all people with risk factors or confirmed CVD should be aware of their risk of cardiovascular events and be encouraged to reduce their risk level [4].

Research results have indicated that the risk of cardiovascular events among patients with CVD is manageable and preventable [1], [8], [9]. The World Health Organization (WHO) suggests reducing the risk of cardiovascular events through school, worksite, or community-based approaches. This approach has been demonstrated to effectively help patients in promoting higher quality of life and reducing the fatal risk of cardiac diseases [10], [11]. Moreover, several 
risk factors among patients with CVD are modifiable by addressing behavioral changes, in terms of healthpromoting behaviors (HPB), such as smoking cessation, vegetable and fruit consumption, low sodium intake, regular physical activities, weight control, and limitation on alcohol intake [1]. The HPB are associated with low mortality and morbidity among patients with CVD [12].

HPB, according to the original explanation by Pender, refer to all approaches and expressions of actualizing action to sustain and increase personal wellbeing, self-actualization, and fulfillment [13]. The HPB also indicate promotion and prevention of advanced degradation of the present disease state through personal responsibility and commitment for a healthy lifestyle [14], [15]. Pender described HPB into six approaches as physical activity, spiritual growth, health responsibility, interpersonal relationship, nutrition, and stress management (SM) [13]. Several studies showed that HPB can help to promote and preserve independence, health state, increase quality of life, and lower medical costs [11], [12], [16], [17]. In advanced cases, among patients with CVD, engagement in HPB has been known to assist in preventing premature death and experiencing less burden of disability [9], [12].

The features of HPB may be different between developed and developing countries [16]. Among the six approaches of HPB, spiritual growth and interpersonal relationships might contribute to particular roles in healthy lifestyle behaviors. In a developing country, for instance in Indonesia, the religious atmosphere is strict and the collectivist culture exists [18], which assists people to become interdependent and connects them to communal goals as a group identity [19]. The exploration of the unique contribution of HPB in a developing country with a collectivist culture may provide specific needs and interventions among this population. At present, the information related to this topic is limited.

HPB among patients with CVD may stimulate behavioral changes that affect the risk of cardiovascular events [9], [12]. However, there is still very limited information about the relationship between HPB and the risk of cardiovascular events. Therefore, the purpose of this study was to examine the relationship between HPB and the risk of cardiovascular events in patients with CVD in Indonesia. Furthermore, the researchers aimed to explore the predicting factors of HPB among patients with CVD.

\section{Methods}

\section{Design and participants}

A cross-sectional study was conducted with a descriptive and correlative design. Multistage cluster sampling method was applied to select participants. First, the researchers randomly selected participants using cluster random sampling based on the village areas between August and October 2017. One village in Yogyakarta was randomly selected using a simple lottery. Approaching participants were continued using convenience sampling in the chosen village using inclusion and exclusion criteria. The inclusion criteria were: Adult patients (more than 18 years old) who had confirmed diagnosis as CVD (i.e. heart failure, hypertension, coronary heart disease, stroke, and other peripheral vascular diseases) and understood Bahasa Indonesia. Patients who had confirmed cognitive and/or psychiatric problems and were unable to fill out questionnaires (i.e. limited extremities' function related to stroke or post cardiac arrest) were excluded from the study.

The estimated sample size was calculated using $G^{*}$ power software 3.1.9.2 with $F$ test for logistic regression analysis with the assumption of $\alpha=0.05$, effect size $=0.15$ [20], power level $=0.80,95 \%$ confidence interval $(\mathrm{Cl})$, and considering 12 predictors to be analyzed. The effect size was based on the Hamilton et al. study that analyzed HPB [12]. A minimum sample required 127 and after adjusting for $10 \%$ missing data, the study needed a minimum of 140 participants.

\section{Measurements}

The demographic data were recorded using a checklist including age, gender, educational level, working status, monthly income, marital status, comorbidity, type of CVDs, systolic and diastolic blood pressure (BP), dyslipidemia, body mass index (BMI), and cholesterol. Non-fasting blood cholesterol level was measured as recommended [3] and classified as dyslipidemia when more than $200 \mathrm{mg} / \mathrm{dl}$. BP was taken twice in a seated or lying position at the beginning and end of the procedure. The mean of the two measurements of BP was documented [21].

The HPB variables were measured using the health promoting lifestyle profile 2 (HPLP) [22]. The HPLP2 was developed according to Health Promoting Model [13], consisting of 52 items to understand individual engagement in health-promoting and healthrelated behaviors using a Likert scale from one (never) to four (routine) for each item. There are six subscales in the HPLP2 including: (1) Physical activity, (2) spiritual growth, (3) health responsibility, (4) interpersonal relationship, (5) nutrition, and (6) stress management. The possible total score ranged between 52 and 208 with the average score between one and four, which implied how the individual applies HPB. It is suggested to calculate the mean of total and subscales rather than sum scores. The higher scores indicated higher engagement in a healthy lifestyle. The instrument has been widely used in nursing and medical research with well-established validity and reliability [9], [12], [22]. Pretesting results indicated that the HPLPI2-Indonesian version (I-HPLP2) is valid and reliable with CVI 0.830.96 and Cronbach's alpha coefficient $=0.81$ [23]. 
Patients with CVD have a risk of cardiovascular events such as a heart attack and stroke. It can be assessed using the WHO/International Society of Hypertension (ISH) Risk Prediction Chart which is a common instrument used to identify the 10-year risk of fatal or non-fatal cardiovascular events [6], [16], [24]. The risk is determined based on age, gender, systolic BP, smoking status, total blood cholesterol, and presence or absence of diabetes. The chart is available for 14 epidemiological sub-regions for both with and without blood cholesterol data [3], [5]. For Indonesia, the WHO/ ISH Risk Prediction Chart SEAR $B$ is suitable to use [3], [5], [6], [7]. It is an easy and simple tool to classify the risk of cardiovascular events among patients with CVD, particularly for the primary health center $(\mathrm{PHC})$ units. The risk chart proposes five colors; green, yellow, orange, red, and dark red that indicate three risk levels, that is, low risk ( $<10 \%$ and green color), moderate risk (10-19\% and yellow color), and high/veryhigh-risk (20-29\%, orange color and $\geq 30 \%$, red or dark red). High and very high risks have similar treatments; therefore, they could be classified as one group [6].

\section{Data collection}

Procedures for data collection in this present study were initiated by submitting ethical clearance to the Institutional Research Board (IRB). After obtaining the approval, the researchers requested the official permission of the PHC units and local government for data collection and conducted a short training program for five research assistants (RAs). Training materials focused on purpose, inclusion and exclusion criteria, measurements, data collecting protocol, informed consent, and coding process. To make sure there were appropriate and equal understandings, the RAs simulated measuring height, weight, and BP and interviewed random subjects.

At the beginning, the researchers collected a list of cardiovascular patients from the PHC units and divided all participants into five groups based on the village areas where they live as a cluster. A random procedure using the clustersampling method selected potential participants. In the selected village, researchers approached the participants using purposive sampling based on inclusion and exclusion criteria. Then, the RAs contacted and visited the potential participants at home. They explained the research purpose and participant's task as the commencement of protocol. If potential participants agreed to participate, RAs asked them to sign an informed consent form and then measured their body height, weight, BP, and non-fasting blood cholesterol. Participants were then asked to answer the questionnaire right after the biological measurements. The RAs checked the completed questionnaire and then kept them in an envelope.

\section{Ethical considerations}

The ethical clearance approval from the IRB committee had been granted. Participants received information about the research and signed informed consent forms before joining the study. No identifiable information was requested. Each participant was coded with a number to prevent the identification of his/her participation. They were informed they could withdraw from the study at any time and whether they participate or not would not affect their medical treatment.

\section{Data analysis}

All data wereanalyzed using SPSS version 20 with a significant level of $p<0.05$. Both results of the ShapiroWilk test $(p=0.159)$ and Kolmogorov-Smirnov test $(p=$ 0.200 ) implied the homogeneity and normal distribution of the data [25]. Mean, median, frequency, and percentages were used for describing the demographic data, HPB, and risk of cardiovascular events. Pearson correlation analysis assessed the association between HPB and the risk of cardiovascular levels. One-way ANOVA analysis was used to identify HPB among different risk groups of cardiovascular events and Tukey HSD followed as a post hoc test. To explore the HPB, hierarchical multiple linear regressions analyzes were applied using three-steps, including patient characteristics, health-related variables, and risk of cardiovascular events.

\section{Results}

\section{Participant characteristics}

A total of 170 participants were invited and only three persons refused to join so there was a response rate of $98.2 \%$ where hypertension led (92.8\%) among other CVDs. The average age was 60 years old $(S D=11)$. The majority of participants, as shown in Table 1, were female $(61.7 \%)$, not working $(67.1 \%)$, and low monthly income $(86.2 \%)$, married $(76 \%)$ and had a low education level (elementary or below about $49.7 \%$ ), with dyslipidemia (55.7\%) and had normal BMI (53.9\%).

\section{events}

\section{The HPB and risk level of cardiovascular}

As shown in Table 1, the mean of HPB was $2.81 \pm 0.33$, indicating better engagement of HPB. The range of means for the subscales was between 2.32 and 3.22. The highest one was interpersonal relationship (IR, M = $3.22 \pm 0.49$ ), followed by spiritual growth (SG, $M=3.08 \pm 0.48)$ while the lowest one was the physical activity (PA, $M=2.32 \pm 0.68)$ subscale. Interestingly, mean scores of IR, SG, and stress management (SM) were more than three.

Risk level of cardiovascular events was widely distributed among participants. Nearly, a half of 
Table 1: Participants' characteristics, health-promoting behaviors and risk of cardiovascular events $(n=167)$

\begin{tabular}{|c|c|c|c|c|}
\hline Variables & Category/IS & $\mathrm{M} \pm \mathrm{SD}$ & $\mathrm{n}$ & $\%$ \\
\hline Age & & $60.20 \pm 11.45$ & & \\
\hline Systolic BP & $\mathrm{mmHg}$ & $159.10 \pm 24.88$ & & \\
\hline Diastolic BP & $\mathrm{mmHg}$ & $90.36 \pm 14.19$ & & \\
\hline \multirow{2}{*}{ Cholesterol } & $\mathrm{mg} / \mathrm{dl}$ & $215.89 \pm 58.64$ & & \\
\hline & $\mathrm{mmol} / \mathrm{l}$ & $5.68 \pm 1.54$ & & \\
\hline BMI & $\mathrm{kg} / \mathrm{m}^{2}$ & $24.06 \pm 4.41$ & & \\
\hline \multirow[t]{2}{*}{ Gender } & Male & & 64 & 38.3 \\
\hline & Female & & 103 & 61.7 \\
\hline \multirow[t]{3}{*}{ Education level } & Elementary or below & & 83 & 49.7 \\
\hline & High school & & 72 & 43.1 \\
\hline & Bachelor or above & & 12 & 7.2 \\
\hline \multirow[t]{2}{*}{ Working status } & Yes & & 55 & 32.9 \\
\hline & No & & 112 & 67.1 \\
\hline Monthly & $0-2$ million & & 144 & 86.2 \\
\hline \multirow{2}{*}{ income (IDR) } & 2-4 million & & 17 & 10.2 \\
\hline & $>4$ million & & 6 & 3.6 \\
\hline \multirow[t]{2}{*}{ Marital status } & Yes & & 127 & 76.0 \\
\hline & No & & 40 & 24.0 \\
\hline \multirow{4}{*}{ BMI Classification } & Underweight & & 12 & 7.2 \\
\hline & Normal & & 90 & 53.9 \\
\hline & Overweight & & 46 & 27.5 \\
\hline & Obesity & & 19 & 11.4 \\
\hline \multirow[t]{5}{*}{ Comorbidity } & Diabetes & & 35 & 21.0 \\
\hline & Smoking & & 23 & 13.8 \\
\hline & History of high cholesterol & & 49 & 29.3 \\
\hline & Family history of CVD & & 71 & 42.5 \\
\hline & Dyslipidemia & & 93 & 55.7 \\
\hline \multirow[t]{4}{*}{ Type of CVD } & Heart failure & & 12 & 7.2 \\
\hline & (History of) stroke & & 13 & 7.8 \\
\hline & Coronary heart diseases & & 8 & 4.8 \\
\hline & Hypertension & & 155 & 92.8 \\
\hline \multirow{7}{*}{$\begin{array}{l}\text { Health-promoting } \\
\text { behaviors }\end{array}$} & Interpersonal relationship ( 9 items) & $3.22 \pm 0.49$ & & \\
\hline & Spiritual growth (nine items) & $3.08 \pm 0.46$ & & \\
\hline & Stress management (eight items) & $3.03 \pm 0.46$ & & \\
\hline & Health responsibility (nine items) & $2.68 \pm 0.68$ & & \\
\hline & Nutrition (nine items) & $2.48 \pm 0.43$ & & \\
\hline & Physical activity (eight items) & $2.32 \pm 0.68$ & & \\
\hline & Total score & $2.81 \pm 0.33$ & & \\
\hline \multirow{3}{*}{$\begin{array}{l}\text { Risk of } \\
\text { cardiovascular } \\
\text { events }\end{array}$} & Low-risk level & & 82 & 49.1 \\
\hline & Moderate-risk level & & 27 & 16.2 \\
\hline & High/very high-risk level & & 58 & 34.7 \\
\hline
\end{tabular}

participants had low risk level $(49.1 \%$ and $n=82)$. It was followed by high/very-high-risk (34.7\% and $n=58)$ and moderate risk $(16.2 \%$ and $n=27)$.

The exploration of HPB in different risk groups of cardiovascular events indicated that only in the nutrition subscale, the significant difference was found $(F=3.37$ and $p=0.037$, Table 2$)$. The post hoc test using Turkey HSD was conducted to identify the difference between two groups for nutrition subscale. Between low and high/very-high risk groups of cardiovascular events, the significant difference was found $(M=0.189 \pm 0.073$ and $p=0.028)$.

The correlation analysis (Table 3 ) showed that the total score of HPB was significantly associated with education level $(r=0.25$ and $p<0.05)$, monthly income $(r=0.19)$, marital status $(r=-0.15)$, presence of diabetes $(r=0.23)$, and smoking status $(r=-0.15)$. The total score of HPB did not show significant differences among risk levels of cardiovascular events.

Among HPB subscales, only nutrition showed significant association with the level of cardiovascular risk $(r=-0.198)$. Almost all of the total scores for HPB and SM subscale had significant correlation with the total and subscales, except for the risk level of cardiovascular events. Remarkably, among the collectivism culture society, both SG and IR subscales,
Table 2: The health-promoting behaviors among different risk groups of cardiovascular events

\begin{tabular}{|c|c|c|c|c|c|}
\hline & Sum of squares & df & Mean Square & $\mathrm{F}$ & Sig. \\
\hline \multicolumn{6}{|l|}{$\mathrm{HR}$} \\
\hline Between groups & 0.476 & 2 & 0.238 & \multirow[t]{3}{*}{0.512} & \multirow[t]{3}{*}{ Ns } \\
\hline Within groups & 76.186 & 164 & 0.465 & & \\
\hline Total & 76.662 & 166 & & & \\
\hline \multicolumn{6}{|l|}{ PA } \\
\hline Between groups & 0.021 & 2 & 0.010 & \multirow[t]{3}{*}{0.022} & \multirow[t]{3}{*}{ Ns } \\
\hline Within groups & 76.715 & 164 & 0.468 & & \\
\hline Total & 76.736 & 166 & & & \\
\hline \multicolumn{6}{|l|}{ NT } \\
\hline Between groups & 1.222 & 2 & 0.611 & \multirow[t]{3}{*}{3.369} & \multirow[t]{3}{*}{$0.037^{*}$} \\
\hline Within groups & 29.737 & 164 & 0.181 & & \\
\hline Total & 30.959 & 166 & & & \\
\hline \multicolumn{6}{|l|}{ SG } \\
\hline Between groups & 0.725 & 2 & 0.362 & \multirow[t]{3}{*}{1.698} & \multirow[t]{3}{*}{ Ns } \\
\hline Within groups & 35.009 & 164 & 0.213 & & \\
\hline Total & 35.733 & 166 & & & \\
\hline \multicolumn{6}{|l|}{ IR } \\
\hline Between groups & 0.171 & 2 & 0.086 & \multirow[t]{3}{*}{0.369} & \multirow[t]{3}{*}{ ns } \\
\hline Within groups & 38.073 & 164 & 0.232 & & \\
\hline Total & 35.733 & 166 & & & \\
\hline \multicolumn{6}{|l|}{ SM } \\
\hline Between groups & 0.330 & 2 & 0.165 & \multirow[t]{3}{*}{0.797} & \multirow[t]{3}{*}{ Ns } \\
\hline Within groups & 33.958 & 164 & 0.207 & & \\
\hline Total & 34.288 & 166 & & & \\
\hline \multicolumn{6}{|l|}{ HPB } \\
\hline Between groups & 0.110 & 2 & 0.055 & \multirow[t]{3}{*}{0.491} & \multirow[t]{3}{*}{ Ns } \\
\hline Within groups & 18.313 & 164 & 0.112 & & \\
\hline Total & 18.423 & 166 & & & \\
\hline
\end{tabular}

showed significant correlation with total score of HPB $(r=0.581$ and $r=0.634$, respectively), $P A(r=0.199$ and $r=0.193)$, and SM subscales $(r=0.369$ and $r=0.365)$ (Table 4).

Table 3: Correlation between demographic data and health promoting behaviors

\begin{tabular}{lll}
\hline Variables & $\mathrm{R}$ & $\mathrm{p}$-value \\
\hline Age & 0.026 & $\mathrm{~ns}$ \\
Gender & 0.062 & $\mathrm{~ns}$ \\
Education level & 0.251 & 0.001 \\
Working status & -0.058 & $\mathrm{~ns}$ \\
Monthly income & 0.185 & 0.008 \\
Marital status & -0.150 & 0.027 \\
Diabetes & 0.227 & 0.002 \\
Hypertension & -0.129 & 0.049 \\
Smoking & -0.145 & 0.031 \\
History of high cholesterol & 0.085 & $\mathrm{~ns}$ \\
Family history of CVD & 0.034 & $\mathrm{~ns}$ \\
Systolic BP & -0.098 & $\mathrm{~ns}$ \\
Diastolic BP & -0.031 & $\mathrm{~ns}$ \\
Cholesterol & 0.067 & $\mathrm{~ns}$ \\
Dyslipidemia & 0.003 & $\mathrm{~ns}$ \\
Body mass index & 0.067 & $\mathrm{~ns}$ \\
\hline
\end{tabular}

BP: Blood pressure, CVD: Cardiovascular diseases, Ns: Not significant.

\section{Prediction of the HPB}

Findings of the hierarchical multiple linear regression analysis showed that age $(\beta=0.247$, $95 \% \mathrm{Cl} 0.003-0.013$, and $\mathrm{p}=0.015)$, education level ( $\beta=0.198,95 \% \mathrm{Cl} 0.005-0.106$, and $p=0.031)$, the presence of diabetes $(\beta=0.166,95 \% \mathrm{Cl} 0.001-0.269$, $\mathrm{p}=0.032)$, and smoking status $(\beta=-0.196,95 \% \mathrm{Cl}$ $-0.372-0.005, p=0.044)$ were significant predictors of HPB among CVD patients. Together, they counted for $20.7 \%$ of the variance in HPB ( $F=1.316, p=0.016)$. However, the risk level of cardiovascular events did not predict HPB (Table 5). The model showed the significant predictors including age, education level, and presence of diabetes. 


\section{Discussion}

Participants' characteristics relate to personal behaviors. In this study, participants were predominantly female, not working and having lower income, lower education, and hypertension with mean of age of 60 years. The findings reflected the national CVD condition where participants' trend had similar data with our study characteristics [26], [27]. Table 4: Correlation between health-promoting behaviors and cardiovascular risk level

\begin{tabular}{|c|c|c|c|c|c|c|c|c|}
\hline & 1.CVD risk & 2.HPB & 3.HR & 4.PA & 5.NT & $6 . S G$ & 7.IR & 8.SM \\
\hline 1. CVD risk & 1 & & & & & & & \\
\hline 2. HPB & ns & 1 & & & & & & \\
\hline 3. HR & ns & $0.685^{\star \star}$ & 1 & & & & & \\
\hline 4. PA & ns & $0.682^{\star \star}$ & $0.439^{\star *}$ & 1 & & & & \\
\hline 5. NT & $-0.198^{*}$ & $0.552^{\star \star}$ & $0.377^{\star *}$ & $0.332^{\star *}$ & 1 & & & \\
\hline 6. SG & ns & $0.581^{\star *}$ & ns & $0.199^{\star *}$ & Ns & 1 & & \\
\hline 7. IR & ns & $0.634^{\star \star}$ & $0.163^{\star \star *}$ & $0.193^{\star}$ & Ns & $0.648^{* *}$ & 1 & \\
\hline 8. SM & ns & $0.582^{* *}$ & $0.250^{* *}$ & $0.203^{*}$ & $0.179^{*}$ & $0.369^{\star *}$ & $0.365^{\star *}$ & 1 \\
\hline
\end{tabular}

Healthy lifestyle profile among patients with CVD is unique. Findings showed that the overall score of HPB was the highest one, compared with the previous studies [15], [16], [28], [29]. It indicated CVD patients in this society engaged in a regular healthy lifestyle. The high score happened because most participants lived in a rural area where there are less stress and more nature in their life. Rural people may have a different perspective of health that is related to working ability and doing routine tasks [30]. The finding highlighted that CVD patients in a rural area had more awareness about their health. It showed that patients with CVD who have diabetes comorbidity, higher income, and higher education but not smoking would have better engagement in healthy lifestyle.

The present study found that the two subscales of HPB and IR and SG subscales showed the highest mean score while PA was at the lowest score. This finding had remarkably higher IR and SG than the previous studies in Canadian and US populations [12], [14], [29]. It may indicate the unique condition of HPB among patients with CVD in developing countries with collectivist cultures. It is known that integration of IR and SG could enhance personal well-being [12] and both were affiliated in term of linkage and inclusiveness. The IR requires strong communication to make meaningful intimacy and attachment whilst SG focuses on inner peace, harmony, and wholeness [16], [22]. Spiritual awareness promoted inner peace and wholeness among transplant recipients and it contributed to positive outlook for the left-ventricular patients with assisted devices [14].

Similar findings of higher IR and SG were found among Korean and Iranian women. However, they had higher means compared with this study. Shin et al. identified mean score of SG among middle-aged Korean women was 3.39 but they had lower IR, which was directly related to the higher SG aspect [31]. It was because the majority of participants in this present study were daily praying and regularly practicing their religious belief. Iranian women were found to have higher IR and SG (3.23 and 3.60, respectively), compared with the present study. They still shared similarities where both studies were conducted in a Muslim developing country where the religious practice is strict. Furthermore, most participants were Iranian women who were household keepers or unemployed, closely equal to this study, which allows more leisure time to focus on healthy lifestyles [16].

The PA score was consistent with former studies as the lowest score [12], [14], [15], [16], [31]. It was supported by a previous study that showed more than half of US women did not have adequate PA [32] and most of their time was for works related to housekeeping [15]. It implies that a particular program to highlight PA or exercise among patients with CVD is recommended.

Table 5: Regression model of health-promoting behaviors prediction

\begin{tabular}{|c|c|c|c|c|c|c|c|c|c|}
\hline \multirow[t]{2}{*}{ Predictors } & \multicolumn{3}{|c|}{ Model $1(n=157)$} & \multicolumn{3}{|c|}{ Model $2(n=141)$} & \multicolumn{3}{|c|}{ Model $3(n=141)$} \\
\hline & $\beta$ & SE & $95 \% \mathrm{Cl}$ & $\beta$ & SE & $95 \% \mathrm{Cl}$ & $\beta$ & SE & $95 \% \mathrm{Cl}$ \\
\hline Age & $0.201^{*}$ & 0.003 & $0.000-0.012$ & $0.247^{*}$ & 0.003 & $0.001-0.013$ & $0.250^{*}$ & 0.003 & $0.001-0.013$ \\
\hline Gender & ns & 0.025 & $0.028-0.127$ & ns & 0.026 & $0.005-106$ & ns & 0.026 & $0.005-0.107$ \\
\hline Education level & $0.239^{*}$ & & & $0.198^{*}$ & & & $0.200^{*}$ & & \\
\hline Working status & ns & & & ns & & & ns & & \\
\hline Income & ns & & & ns & & & ns & & \\
\hline Marital status & ns & & & ns & & & ns & & \\
\hline Blood cholesterol & ns & & & & & & & & \\
\hline Body mass index & ns & & & & & & & & \\
\hline Systolic BP & ns & & & & & & & & \\
\hline Diastolic BP & ns & & & & & & & & \\
\hline Diabetes & & & & $0.166^{*}$ & 0.068 & $0.001-0.269$ & $0.183^{*}$ & 0.069 & $0.013-0.286$ \\
\hline Hypertension & & & & ns & 0.093 & $-0.372-0.005$ & ns & 0.093 & $-0.372-0.005$ \\
\hline Smoking & & & & $-0.196^{*}$ & & & $-0.195^{\star}$ & & \\
\hline Family history & & & & ns & & & ns & & \\
\hline Heart failure & & & & ns & & & ns & & \\
\hline Stroke & & & & ns & & & $\mathrm{ns}$ & & \\
\hline Coronary heart dis. & & & & $\mathrm{ns}$ & & & $\mathrm{ns}$ & & \\
\hline Dyslipidemia & & & & ns & & & & & \\
\hline CVD Risk score & & & & & & & ns & & \\
\hline$R$ square & $11.2 \%$ & & & $20.0 \%$ & & & $20.7 \%$ & & \\
\hline Adjusted R square & $5.5 \%$ & & & $9.7 \%$ & & & $9.8 \%$ & & \\
\hline$\Delta R$ square & - & & & $8.8 \%$ & & & $0.7 \%$ & & \\
\hline Sig. & 0.041 & & & 0.015 & & & 0.016 & & \\
\hline $\mathrm{F}$ & 1.965 & & & 1.798 & & & 1.316 & & \\
\hline
\end{tabular}


Almost half of the participants were in the lowrisk category of cardiovascular events. Conversely, the next following was high/very-high-risk of cardiovascular events in the subsequent 10 years. It infers that the health-promoting programs and risk-reduction interventions should be proposed. The high/veryhigh-risk group needs specific action, not only doing behavioral modification but also intense treatment should be provided [3]. Since patients may not know their actual risk factors or have lower knowledge [28], [29] assessing and enhancing risk reduction behaviors should be considered.

In this study, only the nutrition (NT) subscale showed significant association with risk of cardiovascular events and the difference was substantial among lowand high/very-high-risk groups. The higher engagement in a healthy diet had a lower cardiovascular risk. It is reasonable since determination of risk level of CVD is related to the metabolic factors such as level of cholesterol, blood sugar, and BP, which are known to be associated with fatty, sweet, and salty foods, and are consumed in the daily diet [33] by most patients with CVD who are unaware of the risk [33], [34]. This finding was consistent with a study among Egyptian women with CVD and research in the US elderly population [15], [35].

Risk level of CVD did not show significant association with HPB. It was in contrast with the previous study among high-risk Egyptian women [15]. Non-significant associations between CVD risk level and overall HPB score occurred because most invited participants were at the non-high/very-high-risk group and mostly had low and moderate risk levels. Mokadem identified the positive correlation existed for the major participants with high-risk level of CVD who are more vulnerable participants [15]. The NT score was also known to be correlated with risk of cardiovascular events and HPB [35]. In this study, NT was revealed as the second lowest mean score and may not contribute to significant association between risk of cardiovascular events and HPB. There was possibly another reason for this non-significant finding in the present study. The higher finding of the overall mean score of HPB may not only be due to the high/very-high-risk groups. It may be reflecting the overall constructive awareness of healthy lifestyles that existed and was allocated in various risk levels of CVD.

Demographic characteristics, such as the age, education level, diabetes comorbidity, and smoking, did explain one-fifth variation of HPB. It was consistent with the previous studies [16], [36], [37] but different with other studies [15], [28]. It was explained since younger people typically felt good and ignored their health status whereas the lower education people did not notice health as a priority [16]. Both then lead to invulnerable a feeling, which was followed by non-regular action of healthy lifestyle in their daily life. Meanwhile, the older persons were showing their willingness and readinesses to engage with healthy behaviors while higher education subjects referred to their advanced accessibility to health information and were easily engaged in following the advice [16], [36]. The new outcome was seen when the presence of diabetes and smoking status significantly contributed in predicting HPB among this population. This was explained by CVD patients with diabetes comorbidity and nonsmoking patients who showed more commitment in risk reducing behavior.

\section{Study limitations}

Findings in this study revealed some linked evidence of HPB and risk of cardiovascular events among patients with CVD in a developing country. However, there remained some limitations in the established site of data collection and definite measurements. This study was accomplished in a particular area at Special Region of Yogyakarta Province, Indonesia, where the highest prevalence of CVD occurred. The area of data collection was concentrated in one location, which was randomly designated due to the sampling technique. The next project should elaborate into multi sites for data collection and recruit more CVD patients. Epidemiological study over the entire area and site would result in more rigorous findings. An all-inclusive survey would provide a holistic map of cardiovascular risks and patterns in HPB, reflecting healthy lifestyles, which are habitual behaviors among individuals. Nonetheless, data were only measured at one site once. Longitudinal research with repetitive measurements should be considered as the following study. Several levels of data collection on HPB would postulate nearly tangible behaviors.

\section{Conclusion}

Among HPB subscales, only nutrition indicated a significant correlation with risk of cardiovascular events. Interestingly, interpersonal relationships and spiritual growth showed higher scores among CVD patients in this specific collectivist culture society, which showed particular aspects to be considered. Even though the level of CVD risk could not predict HPB, demographic and health-related variables explained HPB by accounting for one-fifth of variance. The regression model indicated that HPB was predicted by age, education level, presence of diabetes, and smoking status.

Further study focusing on HPB among high/ very-high-risk population of cardiovascular events is recommended. Moreover, certain characteristic of population among CVD patients; such as younger, low education level, and non-smokers, should be considered 
as determining factors of HPB. This specific population is vulnerable and needs definite action for preventing unexpected cardiovascular events. The present report is a primary step for the following milestone in understanding HPB and risk of cardiovascular events.

Understanding of the HPB and risk level of cardiovascular events is a primary step before designing tailor-made programs among patients with CVD. High/very-high-risk of cardiovascular events, which accounted as the second major risk level, implies an urge for action to perform health promotion and prevention. The authorities of stakeholders should consider that a tailor-made health-promoting program should be proposed particularly to increase physical activity and healthy nutrition among patients with CVD. From the study findings, nutrition was significantly associated with risk of cardiovascular events and the difference was between low and high/very-high-risk groups. Thus, healthcare workers need to be concerned to promote healthy eating among CVD patients to assist them in reducing the risk of cardiovascular events. As a nurse working with CVD patients, basic information of HPB and risk level of cardiovascular events would help to support healthy lifestyle promotion, which, in turn, would aid in preventing fatal events in CVD. Furthermore, considering special needs among patients with CVD are crucial to support them within their cultural perspective.

\section{References}

1. World Health Organization. Cardiovascular Diseases CVDs. Available from: http://www.who.org/WHO\%20_\%20 Cardiovascular\%20diseases\%20(CVDs).htm. [Last accessed on 2020 Aug 17].

2. World Health Organization. Indonesia: Health Profile. 2018. Available from: http://www.who.int/countries/idn/en. [Last accessed on 2020 Aug 17].

3. World Health Organization. Prevention of Cardiovascular Disease: Pocket Guidelines for Assessment and Management of Cardiovascular Risk. $1^{\text {st }}$ ed. Geneva: World Health Organization; 2007.

4. Septiani VE, Wicaksana AL, Sunaryo EY. An overview of cardiovascular risk levels in the working area of Mlati Community Health Center Sleman Yogyakarta. J Keperawatan Klinis Komunitas. 2018;2(2):114-24. https://doi.org/10.30590/ vol1-no2-p72-78

5. Kaptoge S, Pennells L, De Bacquer D, Cooney MT, Kavousi M, Stevens G, et al. World Health Organization cardiovascular disease risk charts: Revised model to estimate risk in 21 global regions. Lancet Global Health. 2019;7(10):e1332-45.

PMid:31488387

6. Wicaksana AL, Cipta A, Yumna NA, Naufal MN. Developing mobile application for predicting risk of cardiovascular event among people with diabetes: design and pilot Study. Indian J Public Health Res Dev. 2021;12(1):530-37. https://doi. org/10.37506/ijphrd.v12i1.13901

7. Aini FN, Wicaksana AL, Pangastuti HS. Risk level of cardiovascular eventamong Type 2 diabetes mellitus.
J Persatuan Perawat Nasional Indones. 2019;4(3):182-92. https://doi.org/10.32419/jppni.v4i3.191

8. Perk J, De Backer G, Gohlke H, Grahama I, Reinera E, Verschurena $\mathrm{M}$, et al. European guidelines on cardiovascular disease prevention in clinical practice. Rev Esp Cardiol. 2012;65(10):937. https://doi.org/10.1016/j.rec.2012.08.002

9. Mohsenipouya H, Majlessi F, Shojaeizadeh D, Foroushani AR, Ghafari R, Habibi V, et al. Health-related variables and predictors of health-promoting lifestyle in cardiovascular disease patients. Electron Physician. 2016;8(4):2274-80. https://doi. org/10.19082/2274

PMid:27280004

10. Park $\mathrm{HC}, \mathrm{Oh} \mathrm{J}$. Factor affecting health promoting behaviors in patients with cardiovascular diseases. Healthcare. 2021;9(1):60. PMid:33435583

11. Huang HC, Chou CT, Lin KC, Chao YC. The relationships between disability level, health promoting lifestyle, and quality of life in the outpatients with systemic lupus erythematosus. J Nurs Res. 2007;15(1):21-31. https://doi.org/10.1097/01. jnr.0000387596.32532.54 PMid: 17370230

12. Hamilton J, Kives K, Micevski V, Grace S. Time perspective and health-promoting behavior in a cardiac rehabilitation population. Behav Med. 2003;28(4):132-9. https://doi. org/10.1080/08964280309596051

PMid: 14663920

13. Pender N, Murdaugh C, Parsons M. The promotion model. Health Promot Nurs Pract. 2002;4:59-79.

14. Salyer J, Flattery MP, Joyner PL, Elswick RK. Lifestyle and quality of life in long-term cardiac transplant recipients. J Heart Lung Transpl. 2003;22(3):309-21. https://doi.org/10.1016/ s1053-2498(02)00552-1 PMid:12633699

15. Mokadem NM. Health promoting lifestyle behavior among high risk for cardiovascular diseases. Med J Cairo Univ. 2013;81(1):83-8.

16. Enjezab B, Farajzadegan Z, Taleghani F, Aflatoonian A, Morowatisharifabadm MA. Health promoting behaviors in a population-based sample of middle-aged women and its relevant factors in Yazd, Iran. Int J Prev Med. 2011;3(1):S191-8. PMid:22826765

17. Hua Y, Wang B, Wallen G, Shao P, Ni C, Hua Q. Healthpromoting lifestyles and depression in urban elderly Chinese. PLoS One. 2015;10(3):e0117998. https://doi.org/10.1371/ journal.pone.0117998 PMid:25781326

18. Alam SS, Sayuti MN. Applying the theory of planned behavior (TPB) in halal food purchasing. Int $\mathrm{J}$ Commerce Manage. 2011;21(1):8-20. https://doi.org/10.1108/10569211111111676

19. BonneK, Vermeirl,Bergeaud-BlacklerF, VerbekeW.Determinants of halal meat consumption in France. BrFood J. 2007;109(5):36786. https://doi.org/10.1108/0070700710746786

20. Hulley SB, Cummings SR, Browner WS, Grady DG, Newman, TB. Designing Clinical Research. $3^{\text {th }}$ ed. Philadelphia, PA: Lippincott Williams and Wilkins; 2013.

21. Wicaksana AL, Wang ST. Psychometric testing of the Indonesian version of dietary sodium restriction questionnaire among patients with hypertension. Asian Nurs Res. 2018;12(4):279-85. https://doi.org/10.1016/j.anr.2018.10.005 PMid:30394353

22. Walker SN, Hill-Polerecky DM. Psychometric Evaluation of the Health-promoting Lifestyle Profile II. Unpublished Manuscript. Nebraska: University of Nebraska Medical Center; 1996.

23. Destiana AK, Wicaksana AL, Sunaryo EY. Validity and Reliability of Health Promoting Lifestyle Profile ii on Patients with 
Cardiovascular Diseases in Puskesmas Depok Yogyakarta. Unpublished Thesis. Indonesia: Universitas Gadjah Mada; 2018. https://doi.org/10.20886/jpth.2015.9.3.189-202

24. Conroy R. Estimation of ten-year risk of fatal cardiovascular disease in Europe: The SCORE project. Eur Heart J. 2003;24(11):987-1003. https://doi.org/10.1016/ s0195-668x(03)00114-3

25. Plichta SB, Kelvin EA. Munro's Statistical Methods for Health Care Research. $6^{\text {th }}$ ed. Philadelphia, PA: Wolters Kluwer/ Lippincott Williams and Wilkins; 2013.

26. Kementerian Kesehatan Republic Indonesia. The Main Results of Riskesdas 2018. Available from: http://www.depkes. go.id/resources/download/infoterkini/materi_rakorpop_2018/ Hasil\%20Riskesdas.2020. [Last accessed on 2020 Aug 20].

27. Jumayanti J, Wicaksana AL, Sunaryo EY. Quality of life among patients with cardiovascular diseases in Yogyakarta. J Kesehatan. 2020;13(1):1-12. https://doi.org/10.23917/ jk.v13i1.11096

28. Oliver-McNeil S, Artinian NT. Women's perceptions of personal cardiovascular risk and their risk-reducing behaviors. Am J Crit Care. 2002;11(3):221-7. https://doi.org/10.4037/ajcc2002.11.3.221 PMid:12022485

29. Thanavaro JL, Moore SM, Anthony M, Narsavage G, Delicath T. Predictors of health promotion behavior in women without prior history of coronary heart disease. Appl Nurs Res. 2006;19(3):149-55. https://doi.org/10.1016/j.apnr.2005.07.006 PMid:16877194

30. Pierce C. The impact of culture on rural women's descriptions of health. J Multicult Nurs Health. 2001;7(1):50-3.

31. Shin $H$, Lee J, Lee $K$, Song $Y$. Health behavioral patterns associated with psychologic distress among middle-aged Korean women. Asian Nurs Res. 2007;1(1):61-7. https://doi. org/10.1016/s1976-1317(08)60009-2

PMid:25030544

32. National Center for Chronic Disease Prevention and Health Promotion. Nutritional and Physical Activity: US Physical Activity and Statistic: State Demographic Data Comparison. Atlanta, US: Health and Social Service; 2003.

33. Wicaksana AL. Knowledge, attitude and behavior toward dietary salt: The nescience among hypertensive patients in Indonesia. Int J Res Med Sci. 2017;5(8):3413-9. https://doi. org/10.18203/2320-6012.ijrms20173532

34. Wicaksana AL, Yen M, Wang ST, Fetzer SJ. Determinant of high-sodium food intake among Indonesian patients with hypertension. J Cardiovasc Nurs. 2020. https://doi.org/10.1097/ jcn.0000000000000743

PMid:32796228

35. Speake D, Cowart M, Pellet K. Health perceptions and lifestyles of the elderly. Res Nurs Health. 1989;12(2):93-100. https://doi. org/10.1002/nur.4770120206

PMid:2704843

36. Lee $F$, Wang $H$. A preliminary study of a health-promoting lifestyle among Southeast Asian women in Taiwan. Kaohsiung J Med Sci. 2005;21:114-20. https://doi.org/10.1016/ s1607-551x(09)70287-6

37. Morowatisharifabad M, Ghofranipour F, Heidarnia A, Ruchi G, Ehrampoush M. Self-efficacy and health promotion behaviors of older adults in Iran. Soc Behav Pers Int J. 2006;34(7):759-68. https://doi.org/10.2224/sbp.2006.34.7.759 